\section{New plan for Mono Lake}

\section{San Francisco}

Mono Lake, in northern California, is a unique ecological site, with hundreds of migratory bird species attracted to the algae and brine shrimp that thrive in its alkaline waters, and a tourist attraction too, drawing hundreds of thousands of visitors every year to see the spectacular limestone tufa towers as well as the wildlife. But since 1941 the level of the lake has fallen 41 feet, as the city of Los Angeles has drawn drinking water from four of the five major feeder streams, and the increasing alkalinity threatens to kill the lake. In an attempt to help resolve one of California's most bitterly fought environmental battles, a bill signed into law late last month offers Los Angeles up to $\$ 60$ million if it can find its water elsewhere.

This rich diversity is threatened by the loss of water; the demands of Los Angeles have led to a halving of the lake's volume and a doubling of its salinity. Partial exposure of the alkali-covered lake bed has, according to some, produced a toxic dust laced with arsenic and selenium.

The new legislation will not by itself save the lake, but was endorsed by all parties in the fight and marks a new and potentially pivotal state presence in the decade-long dispute.

Martha Davis, executive director of the Mono Lake Committee, praised the bill for its provision of an incentive for finding alternative sources of water.

Given Los Angeles' current annual water consumption, it has been estimated that the lake's ecosystem will collapse early in the next century. But the city, which receives about 17 per cent of its water from the Mono Lake stream diversions, disputes this and other conclusions.

Several lawsuits surround the Mono Lake controversy, but all have been suspended while the state of California undertakes an exhaustive review, estimated to be finished in late 1993, of the water licences.

The state's offer of $\$ 60$ million is designed to coincide with this effort, and is good only if a compromise solution is reached by January 1994. Although Los Angeles supports the legislation, the money is probably a drop in the ocean compared to what is needed. Mitchell Kodama, manager of Mono Basin issues for the Los Angeles Department of Water and Power, guesses that billions of dollars over the next 50 years will be needed to find new water and power supplies, and says that resolving the issue will be impractical without federal assistance, something that Senator Pete Wilson (Republican, California) is expected to propose soon.

Robert Buderl

\title{
Industry must help science
}

\section{London}

SOVIET industry must take responsibility for helping to solve scientific and technical problems, Deputy Premier Lev Voronin told the Supreme Soviet at the end of last month. Presenting the draft budget for 1990 , he rebuked industrial managers for having failed to respond to recent economic reforms. The restructuring of the Soviet economy calls for enterprises to channel their profits into the development and introduction of new, more productive technologies. But the managers, Voronin said, are actually showing less interest in this field.

The old system of central planning with its rigid targets imposed financial penalties on enterprises which closed down temporarily for retooling, even if the longterm result was greater productivity and higher-quality output. As a result, at the end of the Brezhnev era, there was an ever-growing time gap between technological development and its innovation in industry, sometimes of 10 years or more. Furthermore, the subordination of the major part of the applied research sector to the various industrial ministries meant that much work was duplicated and made interdisciplinary collaboration between institutes under different ministries virtually impossible. A side-effect of the subordination of these 'branch' institutes to their ministries, and hence to a specific industry, was the extremely narrow professional specialization of young scientists.

Mr Mikhail Gorbachev's solution was to advocate the establishment of 'interbranch scientific and technical complexes (IBSTCs) to draw together industry and technological research and to break down the bureaucratic barriers to cooperation. Implementing this proposal has proved a slow task.

The Soviet leadership is still firmly committed to these complexes which, Voronin said, will be responsible for a "substantial volume" of the "state order" for research - that is, the priority research areas still controlled by the central planners. In spite of the delegation of much problem-solving research to the decision of industrial managers, the state sector still has a substantial role to play. During the next year, Voronin said, 59 new testing and pilot-production facilities will be commissioned to "consolidate the material base of scientific organizations fulfilling the state programmes".

Not all Soviet scientists, however, share Gorbachev's enthusiasm for the IBSTCs. For many years, Soviet technologists have found themselves on the losing end of a 'two cultures' debate with the 'fundamental' researchers. Subordination to the industrial ministries, the latter said, has made applied research the "handmaiden of bureaucracy". In a counter-attack just published in Priroda, the popular-science monthly of the Soviet Academy of Sciences, Academician Lev Tauson, director of the Vinogradov Geophysical Institute of the Siberian Branch of the Soviet Academy of Sciences, called for the establishment of a new Academy of Technical Sciences, analogous to the existing agricultural and medical academies. Tauson argued that ministries are interested in short-term solutions to specific problems. An independent technology academy, he said, would cost relatively little to establish, because it would take over the existing 'branch' institutes and the applied science institutes of the Academy of Sciences, which would then be left free to pursue fundamental research. Such an academy would be able to see through promising new developments from the initial concept to pilot production. Unfortunately, he admitted, the idea had little chance of success, because the State Committee of Science and Technology still considers that the Soviet Union's industrial problems can best be solved by concentrating financial support on narrowly target-orientated projects and in making 'academic' science ever more utilitarian.

Vera Rich

\section{NEUROSCIENCE}

\section{A new line in 'neurocomputers' \\ London}

AT a conference in Moscow, experts in nonlinear studies decided last month to establish an international centre in Pushchino, Soviet Union, to coordinate work in the development of neurocomputers. The Moscow workshop, Neurocomputers and Attention, was organized by the Academy of Sciences of the USSR and the Centre for Nonlinear Studies (CNLS) of the University of Leeds with the aim of working out a coherent strategy for modelling higher brain functions and designing large-scale neurocomputers.

According to Arun Holden, director of the CNLS, participants at the meeting were attempting to bridge the gap between attention modelling and neurobiology. The Soviets introduced the concept of an 'attentional neurocomputer', and although most Western scientists regarded the idea as a good one, they did not think Soviet technology was sophisticated enough to realize it. The planned international centre was decided upon as a way of combining the different Soviet and US approaches, which Holden believes should greatly speed up the development of a neurocomputer.

Ben Webb 